\title{
Komposisi Makrozoobentos di Sungai Desa Tolomato Kecamatan Suwawa Tengah, Kabupaten Bone Bolango, Provinsi Gorontalo
}

\author{
Composition of the Macrozoobenthic in the River in Tolomato Village, Central \\ Suwawa District, Bone Bolango Regency, Gorontalo Province
}

\author{
Febiyanti Padja $^{1}$, Ade Irma Polamolo ${ }^{1 *}$, Miftahul Khair Kadim² ${ }^{2}$ Nuralim Pasisingi ${ }^{2}$ \\ ${ }^{1}$ Program Sarjana, Fakultas Perikanan dan Ilmu Kelautan, Universitas Negeri Gorontalo, \\ Gorontalo, Indonesia \\ ${ }^{2}$ Jurusan Manajemen Sumber Daya Perairan, Fakultas Perikanan dan Ilmu Kelautan, Universitas \\ Negeri Gorontalo, Gorontalo, Indonesia \\ *Korespondensasi: ipolamolo12@gmail.com
}

\begin{abstract}
ABSTRAK
Sungai Tolomato merupakan sungai kecil yang berada di Desa Tolomato yang terhubung langsung dengan sungai utama yang ada di Provinsi Gorontalo yaitu Sungai Bone. Metode yang digunakan adalah survey dan purposive sampling. Tujuan penelitian untuk mengetahui struktur komunitas makrozoobentos di sungai Tolomato. Hasil penelitian ditemukan 1.181 individu yang terbagi dalam 11 famili. Ditemukan makrozoobentos sebanyak 6 ordo (Diptera, Ephemeroptera, Coleoptera, Tricoptera, Plecoptera, Lepidoptera) dan 11 famili (Chironomidae, Ceratopogoninae, Tabanidae, Limoniidae, Athericidae, Baetidae, Caenidae, Elmidae, Hydropsychidae, Perlodidae, Crambidae) dari kelas insekta. Komposisi makrozoobentos yang paling banyak ditemukan yaitu dari ordo Diptera sebesar $80 \%$.
\end{abstract}

Kata kunci: Komunitas; Makrozoobentos; Sungai; Desa Tolomato

\begin{abstract}
Tolomato Stream is a small river located in Tolomato Village which is directly connected to the main river in Gorontalo Province, namely the Bone River. The method used was a survey and purposive sampling. The research objective was to determine the structure of the macrozoobenthic community in the Tolomato stream. The results showed that 1,181 individuals were divided into 11 families. There were 6 orders of macrozoobenthos (Diptera, Ephemeroptera, Coleoptera, Trichoptera, Plecoptera, Lepidoptera) and 11 families (Chironomidae, Ceratopogonidae, Tabanidae, Limoniidae, Athericidae, Baetidae, Caenidae, Elmidae, Hydropsychidae, Perlodidae, Crambidae classes). The composition of macrozoobenthos that was mostly found was from the Diptera order of $80 \%$.
\end{abstract}

Keywords: Community;Macrozoobenthos;river; Tolomato Village

\section{PENDAHULUAN}

Sungai adalah salah satu ekosistem air tawar yang memiliki peranan sangat penting yaitu sebagai sumber kehidupan bagi masyarakat sekitarnya. Banyak aktivitas manusia baik itu di daerah pedesaan maupun di lingkungan perkotaan yang tidak luput dari pemanfaatan air sungai (Purdyaningrum et al., 2013). Ekosistem sungai sangat dipengaruhi oleh aktivitas manusia (Kadim et al., 2013).

Masuknya buangan dalam jumlah besar dari bagian hulu hingga bagian tengah sungai secara terus menerus akan mengakibatkan sungai tidak mampu lagi 
melakukan pemulihan. Akhirnya akan terjadi gangguan keseimbangan terhadap konsentrasi faktorkimia, fisika, dan biologi dalam sungai (Kadim, 2014).

Perairan sungai Desa Tolomato adalah salah satu anak sungai yang masuk ke dalam sungai Bone yang merupakan sungai terbesar di Gorontalo. Sungaimemiliki fungsi yang sangat penting yaitu sebagai tempat hidup biota perairan termasuk didalamnya yaitu organisme bentos. Zulkifli dan Setiawan (2011) menyatakan bahwa makrozoobentos adalah organisme yang berada di dasar perairan dan memiliki pergerakan relatif lambat, siklus hidup yang relatif lama sehingga memiliki kemampuan untuk merespon kualitas perairan. Selain itu menurut Wanidar et al., (2016) habitat makrozoobentos terdapat di berbagai macam perairan.

Makrozoobentos adalah organisme akuatik yang mendapatkan paparan secara akumulatif, akibat perubahan kualitas air selama hidupnya. Oleh karena itu, organisme ini dapat merefleksikan keadaan lebih awal ketika kondisi lingkungan berubah menjadi buruk. Keadaan ini yang memberikan keuntungan dalam menganalisis kondisi lingkungan, seperti halnya keadaan lingkungan saat sampling (Bahri, 2014). Berdasarkan penjelasan diatas, Informasi tentang komunitas makrozoobentos sangat diperlukan untuk melihat kondisi lingkungan perairan.

Penelitian ini bertujuan untuk mengetahui komposisi dari makrozoobentos yang ada di sungai Tolomato. Penelitian ini diharapkan dapat memberikan informasi mengenai komposisi makrozoobentos terutama yang berada di sungai.

\section{METODE PENELITIAN}

Penelitian ini dilaksanakan pada bulan November sampai Desember 2020 di Sungai Tolomato, Kecamatan Suwawa Tengah, Kabupaten BoneBolango.

Penelitian ini menggunakan metode survei. Penentuan lokasi penelitian ataupun penentuan titik sampling dilakukan dengan menggunakan metode purposive sampling berdasarkan kondisi tata guna lahan atau kondisi ekologinya. Titik 1 adalah kawasan yang masih relatif alami dan belum terdapat banyak gangguan sedangkan Titik 2 merupakan daerah pemukiman warga.

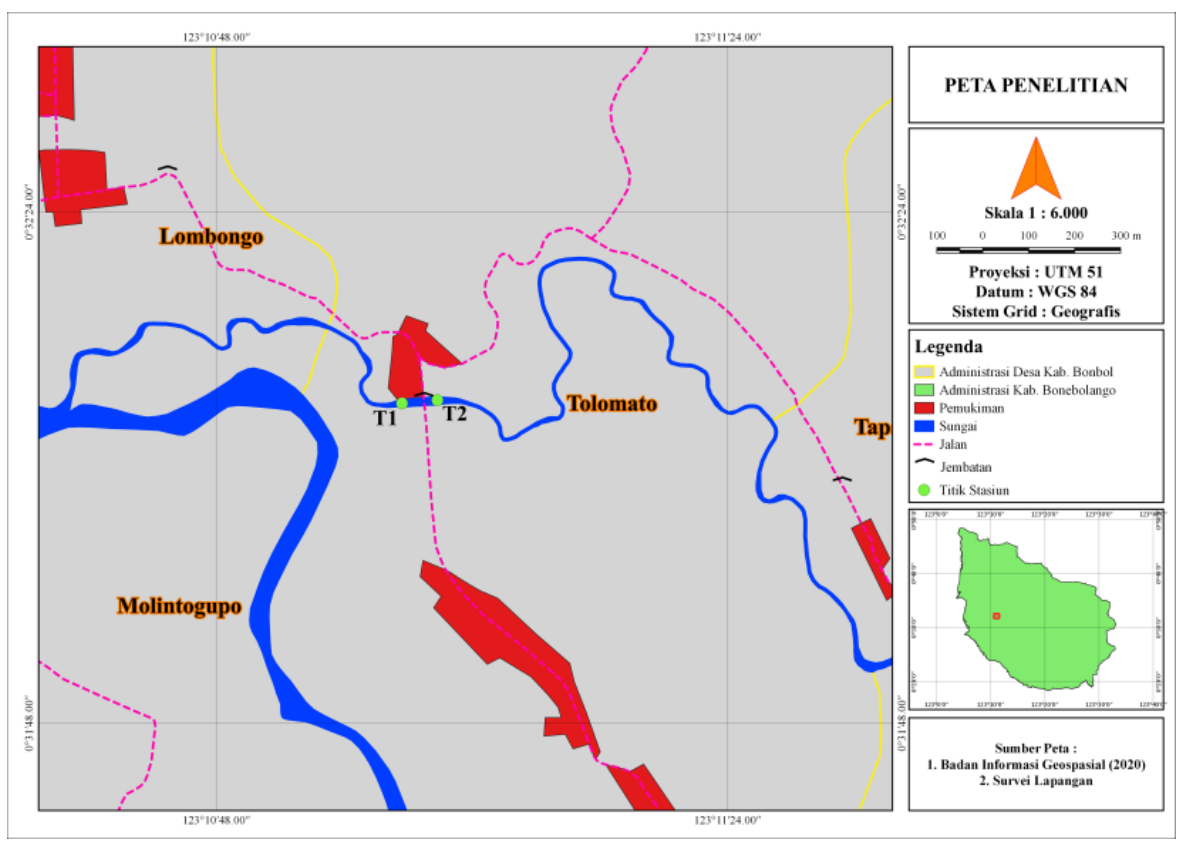

Gambar 1. Sungai Tolomato 


\section{Pengambilan Sampel Makrozoobentos}

Pengambilan sampel dilakukan hanya satu kali saja pada masing-masing titik, dimana jarak antar titik yaitu $100 \mathrm{~m}$. Sampel makrozoobentos diambil menggunakan alat Kick Net pada daerah riffle sepanjang $10 \mathrm{~m}$ ke arah hulu. Kick net memiliki ukuran $220 \times 450 \mathrm{~mm}$ dengan tinggi $100-150 \mathrm{~cm}$ dan ukuran mata jaring $500 \mu \mathrm{m}$. Sampel makrozoobentos yang tersaring dibersihkan dan dipisahkan dari partikel lain seperti sampah organik ataupun lumpur. Sampel dimasukkan ke dalam kantong sampel kemudian diawetkan menggunakan Alkohol 96\%. Sampel selanjutnya dibawa ke Laboratorium Hidrobioekologi dan Biometrik Fakultas Perikanan dan Ilmu Kelautan Universitas Negeri Gorontalo untuk diidentifikasi.

\section{Analisis Data}

Proses identifikasi sampel makrozoobentos menggunakan Mikroskop stereo. Identifikasi dilakukan hingga pada tingkat famili atau sub-famili dengan menggunakan buku identifikasi yang mengacu pada Quigley (1977), Hawking \& Smith (1997) dan De Zwart dan Triverdi (1995). Selanjutnya dilakukan perhitungan kepadatan menggunakan rumus:

$$
D=n i / A
$$

Dimana:

$$
\begin{aligned}
D i= & \begin{array}{l}
\text { Kepadatan makrozoobentos } \\
\text { (individu } \left./ \mathrm{m}^{2}\right)
\end{array} \\
n i= & \begin{array}{l}
\text { Jumlah makrozoobentos yang } \\
\text { ditemukan }
\end{array} \\
A= & \text { Luas area sampling }\left(\mathrm{m}^{2}\right)
\end{aligned}
$$

\section{HASIL DAN PEMBAHASAN}

Berdasarkan pengamatan yang dilakukan, makrozoobentos ditemukan sebanyak 11 famili dan enam ordo dari kelas Insekta. Makrozoobentos yang diperoleh dari hasil penelitian dapat dilihat pada Tabel 1.

Tabel 1. Makrozoobentos yang ditemukan di Sungai Tolomato

\begin{tabular}{lllrr}
\hline No & Ordo & Famili & Titik 1 & Titik 2 \\
\hline 1 & Diptera & Chironomidae & 475 & 467 \\
2 & Diptera & Ceratopogonidae & 12 & 13 \\
3 & Diptera & Tabanidae & 1 & 2 \\
4 & Diptera & Limoniidae & 3 & 0 \\
5 & Diptera & Athericidae & 1 & 1 \\
6 & Ephemeroptera & Baetidae & 100 & 54 \\
7 & Ephemeroptera & Caenidae & 5 & 3 \\
8 & Coleoptera & Almidae & 9 & 10 \\
9 & Trichoptera & Hydropsychidae & 2 & 14 \\
10 & Plecoptera & Perlodidae & 3 & 4 \\
11 & Lepidoptera & Cramdidae & 2 & 0 \\
\hline \multicolumn{2}{c}{ Jumlah } & & 613 & 568 \\
\hline \multicolumn{2}{c}{ Kepadatan } & & $153 \mathrm{ind} / \mathrm{m}^{2}$ & $142 \mathrm{ind} / \mathrm{m}^{2}$ \\
\hline
\end{tabular}

Makrozoobentos yang ditemukan keseluruhannya berasal dari kelas insekta. Menurut Mar'i et al., (2018), hal ini disebabkan karena kelas insekta memiliki kemampuan adaptasi yang baik terhadap berbagai kondisi lingkungan perairan termasuk perairan yang memiliki substrat yang berbatu, kerikil, berpasir dan berlumpur serta arus yang beragam menjadi tempat hidup yang sesuai bagi kelas ini.

Secara umum dapat dilihat pada Tabel 1 bahwa kepadatan makrozoobentos lebih tinggi pada Titik 1 dibandingkan pada Titik 2. Makrozoobentos yang ditemukan di dominasi 
oleh famili Chironomidae dengan individu tertinggi berada pada Titik 1 .

Menurut Kawirian et al., (2020), famili Chironomidae adalah famili dari ordo Diptera yang memiliki penyebaran paling luas, beragam, dan yang paling melimpah dari seluruh famili makroinvertebrata bentik pada ekosistem akuatik terutama sungai pegunungan. Selain itu menurut Purnama (2018), Diptera juga merupakan kelompok yang mendominasi komunitas hewan bentos di sungai karena Diptera memiliki anggota kelompok yang banyak.

\section{Komposisi Makrozoobentos}

Komposisi dan kelimpahan makrozoobenthos bergantung pada sensitifitas atau toleransi terhadap perubahan lingkungan. Setiap komunitas dapat memberikan respon terhadap perubahan kualitas lingkungan dengan menyesuaikan diri pada struktur komunitasnya (Sulphayrin et al., 2018). Komposisi makrozoobentos yang diperoleh dapat dilihat pada Gambar 2.

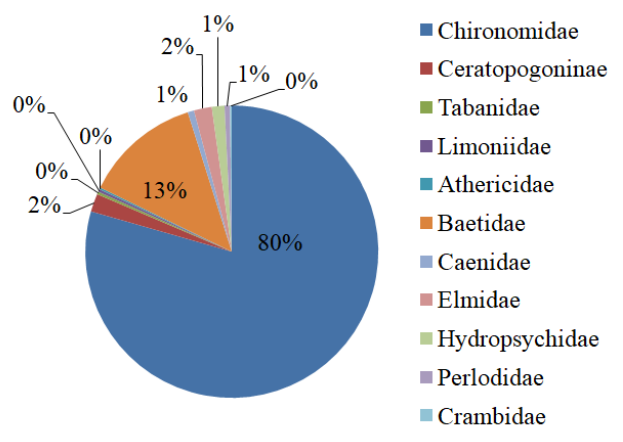

Gambar 2. Diagram komposisi berdasarkan famili makrozoobentos

Komposisi makrozoobentos yang paling banyak ditemukan yaitu dari famili Chironomidae dan komposisi terendah yaitu dari famili Athericidae dan Crambidae. Seperti halnya penelitian Rachman et al., (2016) bahwa komposisi kepadatan makrozoobenthos yang tinggi yaitu dari ordo Diptera famili Chironomidae.
Berdasarkan penelitian yang dilakukan oleh Rijaluddin et al., (2017) Larva Chironomus sp. juga ditemukan hidup melimpah di Situ Kuru. Larva ini termasuk ke dalam ordo diptera. Kehadiran larva Chironomus sp. pada perairan diduga karena adanya sumber makanan yang cukup tinggi bagi larva ini. Larva ini akan memakan hasil sedimentasi dari alga-alga yang sudah mati di dasar perairan.

Menurut Minggawati (2013), keanekaragaman makrozoobentos yang lebih tinggi cenderung berada pada perairan yang dangkal seperti halnya sungai di Desa Tolomato yang memiliki perairan dangkal sehingga intensitas cahaya matahari dapat menembus seluruh badan air hingga mencapai dasar perairan. Daerah dangkal memiliki variasi habitat yang lebih besar dibandingkan daerah yang lebih dalam sehingga cenderung mempunyai makrozoobentos yang beranekaragam.

\section{KESIMPULAN}

Komposisi makrozoobentos yang ditemukan berasal dari kelas insekta yang terdiri dari 6 Ordo dan 11 famili. Makrozoobentos tertinggi berada pada Titik 1 dan terendah pada Titik 2. Makrozoobentos yang ditemukan di dominasi oleh famili Chironomidae.

\section{DAFTAR PUSTAKA}

Bahri, S. (2014). Pengaruh Ukuran Sampel Makrozoobentos Bioindikator Terhadap Penilaian Tingkat Pencemaran Air Sungai. Jurnal Sumber Daya Air, 10(2), 181-194. https://doi.org/10.32679/jsda.v10i2. 135

Hawking, J. H., \& Smith, F. J. (1997). Colour guide to invertebrates of Australian inland waters (Issue 8). Co-operative Research Centre for Freshwater Ecology, MurrayDarling

Kadim, M. K. (2014). Zonasi Sungai 
Umbulrejo di Kecamatan Dampit Kabupaten Malang Berdasarkan Komunitas Makrozoobentos. Jurnal Nike, $2(2)$. https://doi.org/10.37905/.v2i2.1253

Kadim, M. K., Sudaryanti, S., \& Yuli, E. H. (2013). Pencemaran Residu Pestisida Di Sungai Umbulrejo Kecamatan Dampit Kabupaten Malang-Jurnal Manusia Dan Lingkungan, 20(3), 262-268.

Kawirian, R. R., Nurcahyanto, A., Abdillah, D., Panggabean, G. T., Afif, M. I., Pulungan, A., Rahman, C. Q. A., Ishak, M., \& Krisanti, M. (2020). Produktivitas Sekunder Organisme Bentik (Ordo Diptera) di Sungai Cigambreng, Desa Tapos, Kecamatan Tenjolaya, Kabupaten Bogor, Jawa Barat. Journal of Tropical Fisheries Management, 4(1). https://doi.org/10.29244/jppt.v4i1.30 904

Mar'i, H., Izmiarti, I., Nofrita, N. (2017). Komunitas Makrozoobentos di Sungai Gua Pintu Ngalau pada Kawasan Karst di Sumatera Barat. Jurnal Biologi UNAND, 5(1), 4149.

https://doi.org/10.25077/jbioua.5.1.4 $1-49.2017$

Minggawati, I. (2013). Struktur Komunitas Makrozoobentos Di Perairan Rawa Banjiran Sungai Rungan, Kota Palangka Raya. Jurnal Ilmu Hewani Tropika, 2(2), 64-67.

Purdyaningrum, L. R., Rahadian, R., \& Muhammad, F. (2013). Struktur Komunitas Larva Trichoptera Di Sungai Garang Semarang. Jurnal Biologi, 2(4), 54-63.

Purnama, A. A. (2018). Struktur Komunitas Makrozoobentos di Sungai Kumu Kabupaten Rokan Hulu. Agroprimatech, 2(1), 39-42.
Quigley, M. (1977). Invertebrates of streams and rivers. Edward Arnold.

Rachman, H., Priyono, A., \& Wardiatno, Y. (2016). Makrozoobenthos sebagai Bioindikator Kualitas Air Sungai di Sub DAS Ciliwung Hulu. Media Konservasi, 21(3), 261-269. https://doi.org/10.29243/medkon.21. 3.261-269

Rijaluddin, A. F., Wijayanti, F., \& Haryadi, J. (2017). Struktur komunitas makrozoobentos di Situ Gintung, Situ Bungur dan Situ Kuru, Ciputat Timur. Jurnal Teknologi Lingkungan, 18(2), 139-147. https://doi.org/10.29122/jtl.v18i2.16 13

Sulphayrin. Ola, L.O.L., Arami, A. (2018). Komposisi dan Jenis Makrozoobenthos (Infauna) Berdasarkan Ketebalan Substrat Pada Ekosistem Lamun Di Perairan Nambo Sulawesi Tenggara. Jurnal Manajemen Sumber Daya Perairan, 3(4), 343-352.

Wanidar. Sarong, M.A., Dewiyanti, I. (2016). Kajian Struktur Komunitas Makrozoobenthos di Sungai Kuala Tuha Kecamatan Kuala Pesisir Kabupaten Nagan Raya. Ilmiah Mahasiswa Kelautan Dan Perikanan Unsyiah, 1(3), 404-411.

Zulkifli, H., \& Setiawan, D. (2011). Struktur komunitas makrozoobentos di perairan sungai musi kawasan Pulokerto sebagai instrumen biomonitoring. Jurnal Natur Indonesia, 14(1), 95-99. http://repository.unsri.ac.id/id/eprint/ 9106

Zwart, D., Triverdi, R.C. (1995). Taxonomical Key for Biologic Water Quality Determination. Balitbang Project. 
